\title{
ADDRESSING CURRICULUM DECOLONISATION AND EDUCATION FOR SUSTAINABLE DEVELOPMENT THROUGH EPISTEMICALLY DIVERSE CURRICULA
}

\section{K. Padayachee*}

School of Education

e-mail: kershree.padayachee@wits.ac.za

\section{Matimolane*}

School of Animal, Plant and Environmental Sciences

e-mail: mapula.matimolane@wits.ac.za

\section{R. Ganas*}

Centre for Learning Teaching and Development

e-mail: rieta.ganas@wits.ac.za

*University of the Witwatersrand

Johannesburg, South Africa

\section{ABSTRACT}

Transformation in Higher Education has been an ongoing concern in post-apartheid South Africa, especially in light of universities' expected contribution to economic and socio-political transformation. In particular, curriculum transformation has proved challenging, as evidenced in actions and calls by students in recent years for decolonisation of the curriculum. This study, which formed part of an institutional response to the challenge of curriculum transformation and decolonisation, initially sought to examine perceptions of the term "decolonisation" amongst a group of early career lecturers at a leading university in South Africa. Highlighted in the outcomes of the study was the centrality of personal and contextual relevance in notions of decolonised curricula, the impact of curriculum conversations on lecturers' well-being, and the broader implications of responsive and relevant curricula for institutional and societal well-being. In this respect, the findings of the study illustrated the similarities of curriculum decolonisation approaches and the concept of education for sustainable development which is underpinned by the goal of global well-being and the common good. Also highlighted was the need for greater balance between Mode 1 (theoretical) and Mode 2 (contextually relevant) knowledge in curricula, leading us to posit that both curriculum decolonisation and education for sustainable development are equally necessary for institutional and broader societal reform and well-being, and that both imperatives may potentially be achieved by focusing on the principles of epistemically diverse curricula.

Keywords: decolonisation, education for sustainable development, epistemically diverse curricula 


\section{INTRODUCTION}

The transformation of the Higher Education (HE) system has long been recognized by the postapartheid South African government as a potentially powerful lever for improved societal wellbeing, "to redress past inequalities, meet pressing national and international needs, and respond to new realities and opportunities" (DoE White paper 1997, 2). Embedded in this transformation agenda is the desire for social justice and emancipation, two key imperatives which became the generative force for change in HE post-1994. Many policy changes underpinned by these imperatives were consequently implemented since 1994, thus ensuring that university enrolment of students from previously disadvantaged population groups substantially increased, as did enrolment figures in general (Badat 2007). However, the transformation agenda has, to date, been largely limited to improved institutional access and number counting (Ramrathan 2016), as well as the implementation of a variety of foundational programmes. Of particular concern however, is the fact that while university participation rates have increased, university completion rates remain untenably low, especially with regard to students from previously disadvantaged backgrounds (Council on Higher Education 2017). It has been noted, for example, that Black students experience great difficulties in transitioning into the HE system and often remain at the periphery of academic knowledge communities (Bunting 2004; Scott 2009). In contrast, the majority of White students (often from historically advantaged backgrounds) usually possess the requisite cultural capital required to integrate into the $\mathrm{HE}$ system and are able to transition into the academic environment with ease and consequently participate more fully.

The notable difference in participation and completion rates is however, recognized to be symptomatic of the much deeper structural and cultural challenges in HE. It is becoming increasingly evident for instance, that the nature of university curricula, including the types of knowledges selected and emphasized in curricula and the pedagogical approaches used by lecturers to transform and recontextualise disciplinary knowledge (Bernstein 2000), has remained largely unchanged despite significant societal and policy changes, an increasingly diverse student body and changing personal contexts of both students and lecturers. It was therefore, unsurprising when the lag in curriculum transformation and reform became a central theme in the student protests in 2016, when students began demanding "quality, decolonized education". However, precisely what students were asking for in these calls for decolonized education, and whether there existed a shared understanding between students and lecturers of what was meant by curriculum decolonisation, had to be determined within the different institutional contexts. 
Alongside student demands for decolonized higher education, are also calls from various other HE stakeholders. Notably, employers of university graduates, have been calling for universities to adapt and revise their curricula to respond to changing economic and societal needs, and to better prepare students for the rapidly changing world of work (Griesel and Parker 2009). Universities of today (both in South Africa and globally) are also required to be an integral part of the societies they serve and have a pivotal role to play in addressing social injustices and shaping the future world. There is thus, an urgent need for university curricula to be more responsive to changing economic and social realities, a notion also embedded in the National Qualification Framework (Parker and Walters 2008). According to the aims of the $\mathrm{NQF}$, universities should provide higher education that will lead to the preparation of "flexible generalists" (Ball 1996), in reference to the need to equip graduates with the skills to adjust readily to changing work contexts and requirements. This concept resonates with Priestley's (2011) account of generalist attributes, and Barnett's (2009) view that universities increasingly need to prepare adaptable graduates who will be able to survive and thrive in an unknown future world of super-complexity.

The need for university curricula to be adapted to better prepare graduates for current and future uncertainties also echoes the calls for universities to include more explicitly, the critical issue of sustainable development in all university curricula. Cortese (2003) and Wheeler (2000), for example, linked early calls for curriculum transformation to the need to foreground issues of sustainability and sustainable development in university curricula. More recently, LotzSisitka (2017) provided a convincing interpretation of decolonisation theory and practice as a frame for education for sustainable development, to re-orient the purpose of HE to the common good. Similarly, Maringe and Ojo (2017) also highlighted the interconnection between notions of decolonisation of HE in Africa and those of sustainable development in their exploration of the meaning, rationale and approaches for decolonised, sustainable development in African HE.

It is therefore indisputable that universities are currently faced with, and must respond to, two critical but seemingly interwoven challenges. Firstly, universities need to respond to student calls for decolonisation of curricula. Secondly, universities, as intrinsic parts of the broader society, need to align more closely with UNESCO's Education for Sustainable Development Goals (UNESCO 2017), and address calls from local and global stakeholders to integrate education for sustainable development in university curricula to prepare graduates who will be able to deal effectively with the complexities and challenges they will face in the future. A key question is whether both these challenges (i.e, decolonisation and education for sustainable development) can be addressed through a single unifying approach. In other words, could issues of decolonisation of the curriculum be addressed through the explicit inclusion of 
the principles of education for sustainable development, and would the opposite hold true as well? An appropriate starting point in our attempt to answer this question would be to consider current definitions of decolonisation and sustainable development.

\section{DEFINING “DECOLONISATION”}

While the topic of decolonisation as a concept and as a process has been widely interrogated in South African universities (both officially and unofficially amongst staff and students), it remains a highly contested, complex and subjective socio-cultural phenomenon. The work of decolonisation theorists such as Fanon (2004), Spivak (1988) and Wa Thiong'o (1986) clearly illustrate that the decolonisation process is complex and multi-dimensional, replete with conflicts, contradictions and paradoxes. Mbembe (2016), focused on decolonisation in HE in particular, drawing attention to the fact that the decolonisation process encompasses all aspects of being in the HE space. These aspects include the predominantly colonial architecture of university campuses and the Eurocentric academic model that still exists, the authoritative systems of control and management, both of students (through the standardized assessment processes) and increasingly, of university lecturers. Mbembe also pointed out the injustice of the continued existence of syllabi created through epistemic violence and deliberately designed to meet the needs of the colonisers of South Africa and later, of the apartheid system.

The dominance of European culture, language and theories in Higher Education has also been highlighted by other authors as problematic. Wa Thiong'o (1993) for example, suggested a move away from current Eurocentric norms, towards the centering of the African perspective, i.e., the need to place African culture, literature and language at the center of the educational project so that African students may learn about themselves first before learning about people and contexts further afield. There have however, been counter arguments to Wa Thiongo's notion of re-centering the African perspective in university curricula, with suggestions that to re-centre Africa would simply mean replacing one form of knowledge and one worldview with another, an approach that would accomplish little in terms of preparing graduates who can function in both local and global contexts. Thus, for graduates to be locally and globally responsive (as is required for a sustainable future), perhaps what is needed is university curricula that are epistemically diverse and both locally and globally relevant (Mbembe 2016). This broader conception of a decolonized curriculum thus bears striking similarity to the goals of education for sustainable development.

\section{DEFINING "SUSTAINABLE DEVELOPMENT"}

Like the term decolonisation, sustainable development is also contentious and multi-faceted. 
Central to the various definitions and explanations is the awareness of the limited resources of our planet and the potential impact of humans on these resources. Sustainability and sustainable development has therefore been theorized to be development that takes place in a way that does not compromise the needs of future generations (Brundtland 1987). Social justice champions however, argue that an over-emphasis on the protection of biodiversity and other limited natural resources may impact negatively on the needs of the poorer members of society. There is thus, an ongoing tension between ecological sustainability and social justice that cannot be escaped and students of today (citizens and leaders of tomorrow) need to become adept at recognizing and problem solving such tensions. Students need to develop the skills to be able to see and appreciate multiple perspectives, to reflect on actions and resultant impacts and to make objective decisions that are in the best interest of all stakeholders as well as future generations (Budwig 2015; Le Grange 2011; Le Grange, Loubser and Roux 2014). Such reflexivity and meta level cognition requires more than Mode 1 knowledge (Nowotny, Scott and Gibbons 2003) which currently dominates university curricula. Instead, curricula require a delicate balance between conceptual, Mode 1 knowledge and contextually relevant, Mode 2 knowledge (Nowotny, Scott and Gibbons 2003). In other words, education for sustainable development requires curricula that are more epistemically diverse, as suggested by Luckett (2001).

\section{EPISTEMICALLY DIVERSE CURRICULA}

Luckett (2001) proposed a framework for achieving epistemically diverse curricula based on the 4 ways of knowing and learning: 1) traditional cognitive learning of propositional knowledge, 2) learning by doing for the application of disciplinary knowledge; 3) learning experientially through doing with the discipline knowledge; 4) the development of epistemic cognition to think reflexively and contextually about one's learning. A curriculum that addresses these different ways of knowing and learning would therefore enable a greater balance between Mode 1 and Mode 2 or conceptual and contextual knowledge. As discussed by Luckett (2001), such a curriculum would also facilitate the integration of local and global issues as well as the assimilation of Mode 1 disciplinary knowledge with a student's own experiences to create contextual and personal relevance. As such, this model presented an ideal structure for a curriculum that encourages creativity and innovation for sustainable development as well as a possible way of addressing decolonisation. This is because both issues are underscored by the principles of perspective sharing and perspective shifting (as described by Mezirow 1991), self-awareness and reflexivity, and a high level of synthesis and integration of different modes and forms of knowledge (Budwig 2015). It would also significantly enhance students' self-determination and could lead to increased agency. In other words, a decolonized 
curriculum and a curriculum that foregrounds issues of sustainability and sustainable development could both enhance reflexivity and could similarly lead to significant epistemological and ontological shifts in students.

The possibility therefore, exists to be able to address both decolonisation of the curriculum and the principles of sustainable development concomitantly by shifting the emphasis from what we teach and certain types of knowledge that currently dominate university curricula to include how we teach for learning to occur. The challenge remains however, that both decolonisation and sustainable development are still highly contentious and open to interpretation. As such, these issues remain confusing and frustrating for lecturers who are increasingly challenged by students, university managers and the Council on Higher Education (CHE) to address these in their curricula but still uncertain of what must be changed or how to achieve changes. At the same time, students want to see tangible changes to the system whilst they are still in it and are consequently left equally frustrated by the slow pace of transformation in higher education (Costandius and Bitzer 2015).

Deeper engagement with issues of curriculum reform is therefore, crucial at this juncture to create university curricula that are responsive to the needs of a diverse student body, calls for decolonisation and principles of education for sustainable development (Moll 2004). This requires lecturers with curriculum knowledge to enable theoretically informed curriculum decisions during the programme and course development and design processes. However, due to the nature of academic appointments, lecturers are usually not experienced with curriculum development processes and consequently have narrow, technicist and product oriented views of curriculum (Fraser and Bosanquet 2006; Knight 2001). While institutional professional development workshops and programmes can address this, commitments to research and other academic citizenship obligations results in lecturer resistance to attend these (Quinn 2012). Issues of decolonisation and sustainable development that require in depth consideration of complex curriculum design principles, therefore remains a challenge. The student protests of 2015 and 2016 however, highlighted that despite numerous competing agendas, lecturers do need to pay greater attention the complexities of the curriculum design and development.

With this imperative in mind, we sought to gain insights into the meaning of the word decolonisation from two important groups of stakeholders in the decolonisation process viz., lecturers and students. We hoped that such insights could subsequently be used to inform the curriculum reform processes that have been initiated as part of our university's commitment to the provision of decolonized higher education. In the process, we compared and critically reflected on the characteristics and principles embedded in curricula designed with decolonisation in mind, and curricula designed for sustainable development in order to 
determine whether planned institutional initiatives to address these issues independently, could reciprocally address the other.

\section{RESEARCH APPROACH, CONTEXT AND METHODS}

The study adhered to the socio-cultural interpretive paradigm because it focused on understanding the subjective world of human views and experiences in a specific context (Cohen, Manion and Morrison 2013). The intention of adopting this research approach was to understand and make sense of different views on decolonisation while allowing us as the researchers (with varied backgrounds and experiences) to analyze and interpret the data within the bounds of our reflections, assumptions, values and experiences.

\section{Context}

The study was conducted at a research-intensive South African university which, like other higher education institutions of learning in South Africa, is engaging with the notion of calls for "decolonisation of higher education" and higher education curricula and how this might be approached and achieved. Data was collected at a time when the student protests of 2016 were at its height and the issue of decolonisation was being discussed and debated intensely across the university and nationally. As a result of the tensions and uncertainty that characterized those weeks, what emerged at that point was an unprecedented level of anxiety amongst lecturers particularly about decolonisation, as the realization dawned that this was a term that even experienced lecturers seemed unsure of. As academic developers, we therefore decided to engage lecturers enrolled in the University's Early Career Academics Development (ECAD) programme in a discussion on the topic during a community of practice meeting that had been scheduled. We hoped that by doing so, we would provide a safe space in which these lecturers could voice their thoughts about decolonisation and leave empowered to engage further.

\section{Participants}

The participants were a group of 15 academic staff at associate lecturer or lecturer level (hence the classification of early career academics) from all five faculties within the university (viz., Science, Engineering and the Build Environment, Commerce, Law and Management, Health Science and Humanities). The group was therefore, diverse in terms of disciplinary focus, age and race. Given the student protests and the institutional calls for decolonizing the curriculum at that particular time, as facilitators, we were acutely aware of the wellbeing of the lecturers and the need to provide an open, safe and highly collegial atmosphere in order to encourage authentic and honest participation. At the same time, we also sought permission from the 
lecturers to use the insights elicited through their participation, to engage in a subsequent scholarly endeavor to further our collective understanding of decolonisation in higher education. Once permission was obtained and the lecturers had agreed to engage both as members of the community of practice and as research participants, we commenced the workshop with a free writing activity that enabled the lecturers' uninterrupted communicative reflections through writing what decolonisation of the curriculum meant for them personally. Free writing was selected as an appropriate method for this purpose as it is a non-stop writing activity for a period of time without lifting your pen from paper to enable no editing and no censoring of thoughts (Badenhorst, 2007), thus providing an ideal method for the intended purpose of reflection.

The lecturers subsequently engaged in a robust discussion of decolonisation, reflecting on their thoughts captured in the free write as well as their prior conception of the topic based on their experiences and engagements with students and faculty colleagues. The discussion was co-facilitated by two of the researchers involved in this study, who also engaged as coparticipants in the emerging dialogue. Notes were taken of key points that emerged, with clarification sought during the discussion. These notes and the free writing pieces were subsequently analysed by researchers.

\section{Data analysis}

The analysis of the free writes was done through an iterative process, reflecting the authors' understanding and interpretation of lecturers' views on decolonisation. The data analysis incorporated several stages. All three authors read the free writes independently and did a preliminary characterization of the data. The authors then discussed and compared the categorization of data and reached an agreement on the themes that emerged based on several rounds of tabulation and cross analyses. We subsequently advanced our exploration of the understanding of decolonisation by comparing lecturers' responses to students' notions of decolonisation obtained from a manifesto on the topic compiled by a group of 60 Fine Art students in the Faculty of Humanities as part of a class activity and assessment, which was made available to us by the lecturer of the course.

The student manifesto was an outcome of iterative cycles of group discussions on decolonisation held over a period of three weeks. A few months after the student protests had ceased, the lecturer involved in the class activity and a few of the students shared the manifesto and their thoughts on curriculum decolonisation with the academic community during a panel discussion at an institutional teaching and learning symposium. The manifesto was made available to us for purpose of this study without any names or other identifying information. Content analysis of the student manifesto was guided by conceptual constructs on 
decolonisation of curriculum and ESD, and the results were compared with the data obtained from the lecturers' free writes and subsequent discussion.

While the manifesto provided a useful resource of student opinions and views, we noted that because of the nature of the manifesto (i.e., a document that emerged after several weeks of collective student engagement with it), it did not reflect the conflicts, misunderstandings and negotiations that might have formed part of the discussions. It was instead, a synthesized version of the consensus and discussions. On this point, we noted too, that due to the different approaches and time frames for data collection between lecturers and students, the responses between the lecturers who participated in the community of practice discussion and those of the students varied in focus. The discussion and conclusions presented in this article are therefore, bound by the context represented in terms of the sample size, participants characteristics and time and space of the data collection processes.

\section{Ethics}

Ethical issues were addressed through informed consent by the participants of the Early Career Academic Development Programme. Lecturers were informed, upon voluntarily joining the Programme, about intended research studies involving the perceptions of Early Career Academics on various issues in HE, and their consent was sought at the onset to participate in such studies. Lecturers were reminded of this agreement at the start of the community of practice meeting and asked, once again, for their consent. Lecturers' anonymity was also discussed and lecturers were assured that their anonymity would be maintained in any research outputs emerging from their participation. Lecturers were also reminded of their commitment to maintaining the confidentiality of the community of practice discussions, which had also been discussed with them earlier. Only once consent and agreement was obtained from all the lecturers present did the free writing activity commence.

\section{FINDINGS AND DISCUSSION}

The research commenced with the assumption that there would be differences in the perceptions of the term "decolonisation" among lecturers and students. This assumption was based on the various descriptions of the term in the substantial body of literature on decolonisation by scholars like Mbembe (2016) and De Oliveira Andreotti et al. (2015). It was therefore, not surprising to see the challenge of defining the term "decolonisation" emerge strongly as a common theme in the responses of both lecturers and students in their manifesto. However, what was unexpected was the finding that while perceptions were expressed differently amongst lecturers and students, there were more commonalities in their understanding of the term than 
differences. Key themes of personal and contextual relevance of the curriculum and the need to review and reimagine pedagogical strategies emerged from both.

Both students and lecturers indicated the difficulty experienced in attempting to define the term "decolonisation". Lecturers commented that it was difficult to define and unpack the term and that we are yet to have an agreed upon definition. One lecturer also highlighted that decolonisation would mean different things to different people as would curriculum, as indicated by Cornbleth (1988). Students' responses in the manifesto matched those of the lecturers in that they felt there was a lack of clarity on what decolonisation is. Interestingly, students had reported this lack of clarity after three weeks of discussions. However, both lecturers' and students' views aligned with the extensive body of literature discussed earlier, that acknowledges the challenges of attempting to define this term.

Nevertheless, some lecturers felt that a definition, even a loose one, was necessary to move the decolonisation agenda forward. Others however, cautioned against attempts to define the term, since doing so too narrowly could potentially trivialize the depth, complexity and personal relevance of the matter. These comments highlighted the potentially divisive nature of conversations on decolonisation and the inherent challenges of addressing this issue in the South African context.

In contrast to the challenge of providing an unambiguous definition of the term, it appeared easier for both groups to identify the issues of personal and contextual relevance of the curriculum and the revisioning of pedagogical strategies as important aspects of the decolonisation agenda that need attention within the University. Importantly, the specific ideas on the matter of personal relevance expressed by the student in the manifesto and the participating lecturers demonstrated the significant emotional burden that this topic has placed on all stakeholders.

\section{Personal relevance and the classroom as an inclusive, engaging space}

The issue of personal relevance, including power relations and positionality was highlighted strongly in both the students' and lecturers' responses. For students, this feeling was reflected as follows:

"It is essential for both students and lecturers to position themselves as explicitly as possible in the learning environment. This positioning should be aimed at locating each party in the class in relation to each other particularly in term of ideological underpinnings and assumptions." (Students manifesto 2016).

The comment above was followed by mention of the need for greater negotiation and critical engagement in the quest for achieving personal relevance. It was the students' views that: 
"Each learning environment needs to be premised on the concept of negotiation and critical engagement. Neither lecturers nor students should privilege or prescribe ideas over others without engagement." (Students manifesto 2016).

These comments suggest that there may be pre-existing classroom dynamics that maintain the lecturers' positions of power in terms of how the knowledge is shared. This may be problematic for students who, it would seem, increasingly identify themselves as co-creators of the curriculum and active participants in the learning process.

For lecturers, some responses appeared to be more emotionally burdened. For instance, one lecturer talked about wanting to remain distant from the topic as far as possible:

"I feel like I don't have the emotional energy to write about this. This is a very emotional topic at present time in the university and in the country. While I truly appreciate the significance and importance of this, I feel I want to stay distanced for a little longer. I want it to be more a macroand not a micro situation." (Lecturer Free write 2016).

Another lecturer reflected that decolonisation relates to "feelings of self-worth and fitting in". From our perspective, we felt that this statement could relate either to institutional or classroom dynamics. There were also other, more emotionally charged comments such as the following:

"(Decolonisation should) not merely be an attempt to diversify the curriculum in tribute to the rainbow nation ideal of multiculturalism but to challenge the inherent and invisible obstacles for black bodies as students and colleagues ... away with white dominated education." (Lecturer Free write 2016).

The above comment emphasized the highly controversial and emotive nature of the decolonisation agenda, resonating deeply with descriptions of colonialism as a form of physical, psychological or structural violence against marginalized populations (Fanon 2004). As mentioned by another participant, such statements could prove inflammatory and divisive if voiced in arenas outside the safe space of the workshop and could significantly impact on collegiality as well as individual and institutional well-being. However, it is equally important that transgressive voices such as these are heard as it is in those moments of disruption and discomfort that genuine transformation and progress may occur. For the facilitators, this was an important tension to consider and mitigate.

Attention was also drawn by one lecturer to "the importance of acknowledging the internal knowing and knowledge systems that drive our actions and shapes our becoming". The lecturer who wrote this statement also reflected on personal experiences as a student and the impact of lecturer authority in limiting what was taught and learnt, bringing to the fore the issue of pedagogical power and the need for greater negotiation and critical engagement noted by the 
students. This was similar to the responses of another lecturer:

"Decolonisation needs renegotiation of assessment and teaching methodologies. Positionality is key to this in a way that doesn't blame and shame .... We need to shift focus for students to start telling their own stories." (Lecturer Free write 2016)

This lecturer also pointed out the need to "start conversations around mutual respect and sensitizing to other cultures".

These comments emphasized some noteworthy issues. For instance, positionality and power plays are clearly a concern when discussing the topic of decolonisation, as is the case when discussing education for sustainable development, where positionality and power may strongly influence decisions on issues of sustainability. The other related concern is the need for perspective sharing and acknowledgement of the need for different voices to be heard and respected, as well as the need for cultural sensitivity in the classroom, again a point that strongly overlaps with education for sustainable development. However, while these issues are critical for both decolonisation and sustainability, in the context of a multicultural classroom, it may be challenging for all voices to be heard in a fair and pedagogically sound manner.

The solution may lie in a knowledge-based approach to the curriculum (Shay 2013), by integrating existing disciplinary knowledge (Mode 1, conceptual knowledge) together with explicit integration of appropriate, high quality Mode 2 knowledge (Muller 2000; Nowotny, Scott and Gibbons 2003). This approach would require lecturers to draw from a range of different knowers and knowledges from different sites of knowledge production, e.g., indigenous knowledge systems, which some students may be familiar with and use as a starting point for meaningful construction of their disciplinary learning. Indigenous knowledge and other forms of knowledge could thus, be recognized and legitimized as powerful knowledges. This would enrich the curriculum and challenge students to critically explore their own views in relation to the views of others (Phillips and Whatmann 2007).

The knowledge-based approach would not only provide students with a means of contributing to the curriculum by adding their personal knowledge and experiences but it would also create opportunities for developing the skills of recognizing and valuing different perspectives and working in a knowledge-rich environment. Magolda (2001) proposed that lecturers should aim for their students to develop self-identity values, engage with others and develop a shared responsibility for learning while Barnett and Coate (2004) recommended time spent by lecturers on evaluating the three main domains of their curriculum: knowing (knowledge), doing (acting) and being (self). These authors suggested that lecturers should reflect on how their curriculum advances student development as human beings with their own 
sense of self and agency, both of which are crucial in the matters of decolonisation as well as sustainable development.

A consideration of the balance between contextual and conceptual knowledge in the curriculum could also lead to a natural unravelling of the power dynamics between lecturers and students since students would feel that they are being genuinely participatory in the learning process. In this way, the curriculum may become more than just the technicist view of the content and outcomes of individual courses (i.e., a packaged product to be delivered to student) or even the structuring, sequencing and framing of the content (Fraser and Bosanquet 2006; Knight 2001). Instead, it could allow for the curriculum to be perceived as a negotiated process in which institutional graduate identity as well as the critical outcomes are crafted and where issues of both sustainable development and other core contemporary issues may addressed.

\section{Contextual relevance}

Of similar importance to the issue of personal relevance was the issue of contextual relevance. Based on the responses of lecturers and students, contextual responsiveness in this sense relates to curriculum reforms linked to disciplinary, societal (local, regional and global), institutional and structural contexts. Comments from some staff also hinted at Wa Thiong'o's (1993) notion of centering Africa in the curriculum. An example of this was a comment by a lecturer who stated that decolonisation requires:

"keeping what we have but strengthening it with concepts and theories that have emerged from Africa and that is more culturally relevant and contextually relevant; relying on knowledge born from a contextually relevant space." (Lecturer Free write 2016).

Another lecturer who was more specific in terms of relating to Wa Thiong'o's proposition of centering Africa, also highlighted the apparent importance to staff of contextual relevance as seen in the field of knowledge production and recontextualisation (Bernstein 2000):

"(Decolonisation is) to teach what is appropriate for our surroundings; a uniquely African centered approach; surfacing and challenging the underlying western ideologies that inform the very system and structure of tertiary education; not focusing or targeting an international audience; accommodating other paradigms." (Lecturer Free write 2016).

Lecturers were however, cognizant of the fact that curricula cannot be limited to local content alone but needs to addresses national and continental relevance (without neglecting the personal relevance, as discussed in the previous section). This is evident in a lecturer's comment that decolonisation should include: "The use of literature written locally ... but the university serves students from all over the world" (Lecturer Free write 2016).

Students also showed an awareness and appreciation of the influence of globalization and 
internationalization in curriculum reform. It seemed however, that students were suggesting that there was a need for greater rather than less inclusion of issues of global contextual relevance, based on a comment in the student manifesto that the "university environment is disengaged with the world beyond its walls" (Student Manifesto 2016).

In essence, both students and staff are aware of the need for contextually relevant curricula which goes beyond the immediate context. This sentiment reiterates the views of Ogude, Nel, and Oosthuizen (2005) that South African universities need to have relevant curricula to create global and locally relevant graduates and citizens with problem-solving skills that can be adapted to changing environments. Appropriate recontextualization of different forms of knowledge is therefore, a critical aspect of the decolonisation process and equally critical in the curricula designed to sensitize students to issues of sustainable development.

The importance of recontextualization of knowledge (Bernstein 2000) again highlights the value of a well-considered, well planned, epistemically diverse curriculum in the quest for both decolonisation and the preparation of graduates for a sustainable future. It is therefore safe to suggest, as also pointed out by Lotz-Sisitka (2017) and Maringe and Ojo (2017), that it may indeed be possible to reciprocally address both decolonisation and sustainable development through similar approaches to curriculum development and reform, since both are premised on the achievement of a curriculum in which conceptual knowledge is addressed alongside contextual knowledge. However, while this is theoretically possible, there are significant challenges that may stymie the achievement of either, the most significant of these being the lack of knowledge and expertise in curriculum development and design processes amongst lecturers and faculty departments.

\section{Challenges to designing and enacting epistemically diverse curricula, and possible solutions}

To design and develop conceptually and contextually relevant curricula, lecturers will have to draw on their theoretical understanding, frameworks and models of knowledge and knowledge structures as well as curriculum development and design processes. The challenge however, is the perceived resistance of lecturers to engage with these concepts and tools. Traditional isolated pedagogical practices that are deeply entrenched in South African universities and the fact that most lecturers are extremely recalcitrant to change seem to account for the perceived resistance. Compounding this challenge is the fact that most lecturers, globally and locally, have not been prepared to critically engage with the process of curriculum development and design in HE (Quinn 2012) and often resort to their craft knowledge or common sense understanding to complete the complex task of developing and delivering an epistemically diverse curriculum. 
Scott (2009) cautions that common sense understanding or craft knowledge is often not able to solve complex problems and a systematic knowledge of teaching and learning theory and practice is necessary. This point could explain, in part, why the issue of decolonisation of the curriculum and defining the term is so perplexing to lecturers. This issue might however, be mitigated through academic development programmes and workshops aimed at bridging this knowledge gap for lecturers. However, in the context of a research-intensive university where professional development is not mandatory and lecturers are time pressured and heavily focused on research, convincing staff to engage in such activities might yet prove challenging.

\section{CONCLUSION}

Given the high prioritization of the issue of decolonisation of higher education nationally, the equally important global prioritization of education for sustainable development, and the potentially detrimental effects of non-responsiveness on individual, institutional and societal well-being, we believe that academic development should prioritize curriculum knowledge and design as an integral requirement of professional staff development. Informed and contextually relevant curriculum design can enable the integration of the principles of sustainable development whilst responsive to the curriculum decolonisation calls.

Our suggestion therefore, is that universities (and academic development staff in particular) approach the process tentatively by encouraging greater engagement and perspective sharing between different stakeholders, in order to reach greater mutual understanding, and to provide greater exposure to innovative ways of teaching and learning, including the value of epistemically diverse curricula. In this way, lecturers may be sensitised to the critical need to address both decolonisation and education for sustainable development in their curricula (demonstrated in this narrative to be strikingly similar). We further suggest that these endeavours may be substantially bolstered by highlighting for lecturers the similarities noted in this study between the two critical curriculum imperatives of decolonisation and sustainability, and that both could be achieved by striving for more epistemically diverse curricula.

\section{ACKNOWLEDGEMENTS}

All participating staff and students are thanked for their valuable contributions to this research.

\section{REFERENCES}

Badat, S. 2007. Higher education transformation in South Africa post 1994: Towards a critical assessment. CEPD.

Badenhorst, C. M. 2007. Research writing: Breaking the barriers. Pretoria: Van Schaik.

Ball, C. 1996. Life long learning for the $21^{\text {st }}$ century. Keynote address at the $21^{\text {st }}$ Improving University 
Teaching Conference. Nottingham Trent University, Nottingham.

Barnett, R. and K. Coate. 2004. Engaging the curriculum. McGraw-Hill Education (UK).

Barnett, R. 2009. Knowing and becoming in the higher education curriculum. Studies in Higher Education 34(4): 429-440.

Bernstein, B. B. 2000. Pedagogy, symbolic control, and identity: Theory, research, critique. (No. 4). Rowman \& Littlefield.

Brundtland, G. H. 1987. Our common future. Report to the world commission on environmental development. http://www.un-documents.net/our-common-future.pdf

Budwig, N. 2015. Concepts and tools from the learning sciences for linking research, teaching and practice around sustainability issues. Current Opinions in Environmental Sustainability 16: 99104.

Bunting, I. A. 2004. Student retention: A macro perspective from South Africa. In Retention and student success in higher education, ed. M. Yorke and B. Longden, 16-31. Berkshire: The Society for Research into Higher Education \& Open University Press.

Costandius, E. and E. Bitzer. (Eds.). 2015. Engaging higher education curricula: A critical citizenship perspective. Stellenbosch: SUN Press.

Council on Higher Education (CHE). 2017. VitalStats2015 http://www.che.ac.za/media_and_ publications/monitoring-and-evaluation/vitalstats-public-higher-education-2014

Cohen, L., L. Manion and K. Morrison. 2013. Research methods in education. Routledge.

Cornbleth, C. 1988. Curriculum in and out of context. Journal of Curriculum and Supervision 3(2): 8596.

Cortese, A. D. 2003. The critical role of higher education in creating a sustainable future. Planning for Higher Education 31(3): 15-22.

De Oliveira Andreotti, V., S. Stein, C. Ahenakew and D. Hunt. 2015. Mapping interpretations of decolonisation in the context of higher education. Decolonisation: Indigeneity, Education \& Society 4(1).

Department of Education (DoE) R.S.A. 1997. Education White Paper 3: A programme for the transformation of higher education. Pretoria: Department of Education.

Fanon, F. 2004. Wretched of earth. (Translated by P. Philcox). New York, NY: Grove Press.

Fraser, S. P. and A. M. Bosanquet. 2006. “The curriculum? That's just a unit outline, isn't it?” Studies in Higher Education 31: 269-284.

Griesel, H. and B. Parker. 2009. Graduate attributes: A baseline study on South African graduates from the perspective of employers. Pretoria. Higher Education South Africa (HESA).

Knight, P. T. 2001. Complexity and curriculum: A process approach to curriculum-making. Teaching in Higher Education 6(3): 369-381.

Le Grange, L. L. 2011. Sustainability and higher education: From arborescent to rhizomatic thinking. Educational Philosophy and Theory 43(7): 742-754.

Le Grange, L. L., C. Loubser and C. Roux. 2014. Sustainability and education: A critical discussion. In Environmental education and education for sustainability, ed. C. P. Loubser. Van Schaik Publishers, Pretoria South Africa

Lotz-Sisitka, H. B. 2017. Decolonising as future frame for environment and sustainability education. In Envisioning futures for environment and sustainability education, ed. P. Corcoran and J. Weakland, 45-62. Wageningen: Wageningen Academic Publishers.

Luckett, K. 2001. A proposal for an epistemically diverse curriculum for South African higher education in the 21st century. South African Journal of Higher Education 15(2): 49-61.

Magolda, M. B. 2001. Making their own way: Narratives for transforming higher education to promote self-development, 17-32. 
Maringe, F. and E. Ojo. 2017. Sustainable transformation in a rapidly globalizing and decolonizing world: African Higher Education on the brink. In Sustainable transformation in African higher education, ed. F. Maringe and E. Ojo, 25-39. Sense Publishers.

Mbembe, A. J. 2016. Decolonizing the university: New directions. Arts and Humanities in Higher Education 15(1): 29-45.

Mezirow, J. 1991. Transformative dimensions of adult learning. Jossey-Bass, 350 Sansome Street, San Francisco, CA 94104-1310.

Moll, I. 2004. Curriculum responsiveness: The anatomy of a concept. In Curriculum responsiveness: Case studies in higher education, ed. H. Griesel, 1-19. Pretoria: South African Universities ViceChancellors Association.

Muller, J. 2000. What knowledge is of most worth for the millennial citizen? In New knowledge production and its implications for higher education in South Africa, ed A. Kraak, 70-87. Pretoria, South Africa: HSRC Press.

Nowotny, H., P. Scott and M. Gibbons. 2003. Introduction: Mode 2' revisited: The new production of knowledge. Minerva 41(3): 179-194.

Ogude, N., H. Nel and M. Oosthuizen. 2005. The challenge of curriculum responsiveness in South African higher education. Council on Higher Education.

Parker, B. and S. Walters. 2008. Competency-based training and National Qualifications Frameworks: Insights from South Africa. Asia Pacific Education Review 9(1): 70-79.

Phillips, J. and S. Whatmann. 2007. Decolonizing preservice teacher education - reform at many cultural interfaces. In Proceedings of The World of Educational Quality: 2007 AERA Annual Meeting: 194. Chicago, USA.

Priestley, M. 2011. Whatever happened to curriculum theory? Critical realism and curriculum change. Pedagogy, Culture \& Society 19(2): 221-237.

Quinn, L. 2012. Enabling and constraining conditions for academic staff development. In Re-imagining Academic Staff Development: Spaces for Disruption, 27-50.

Ramrathan, L. 2016. Beyond counting the numbers: Shifting higher education transformation into curriculum spaces. Transformation in Higher Education 1(1): a6. http://dx.doi.org/ 10.4102/the.v1i1.6

Scott, I. 2009. Academic development in South African higher education. In Higher Education in South Africa: A scholarly look behind the scenes, 21-47.

Shay, S. 2013. Conceptualising curriculum differentiation in higher education: A sociology of knowledge point of view. British Journal of Sociology of Education 34(4): 563-82.

Spivak, G. C. 1988. Can the subaltern speak? In Marxism and the interpretation of culture, ed. C. Nelson and L. Grossberg, 271-313. Urbana and Chicago. University of Illinois.

UNESCO. 2017. Education for sustainable development goals. http://unesdoc.unesco.org/images/0024/ 002474/247444e.pdf

Wa Thiong'o, N. 1986. Decolonising the mind: The politics of language in African literature. East African Publishers.

Wa Thiong'o, N. 1993. Moving the centre: The struggle for cultural freedoms. James Currey.

Wheeler, K. 2000. Introduction. In Education for a sustainable future, 1-5. Springer US. 